\title{
Evaluation of complicated and uncomplicated parapneumonic effusion in children
}

\author{
Zeynep Gökçe Gayretli-Aydın¹, Gönül Tanır ${ }^{1}$, Gülsüm İclal Bayhan¹, Türkan Aydın-Teke1, \\ Fatma Nur Öz ${ }^{1}$, Özge Metin-Akcan ${ }^{1}$, Ayşe Kaman ${ }^{1}$ \\ ${ }^{1}$ Department of Pediatrics, Division of Pediatric Infectious Diseases Dr. Sami Ulus Maternity and Children's Training and \\ Research Hospital, Ankara, Turkey. \\ E-mail: zggayretli@gmail.com \\ Received: 26th October 2016, Revised: 2nd January 2017, Accepted: 9th March 2017
}

SUMMARY: Gayretli-Aydın ZG, Tanır G, Bayhan Gİ, Aydın-Teke, Öz FN, Metin-Akcan Ö, Kaman A. Evaluation of complicated and uncomplicated parapneumonic effusion in children. Turk J Pediatr 2016; 58: 623-631.

Parapneumonic effusion (PPE) and empyema are most often seen as a complication of bacterial pneumonia and occasionally associated with atypical bacteria or viruses. The aims of this study were to describe and compare demographic characteristics, clinical, laboratory, microbiological findings and treatment modalities of patients with PPE and empyema. We retrospectively reviewed 116 pediatric patients with PPE and empyema. Seventy $(60.3 \%)$ had pleural empyema and 46 patients $(39.6 \%)$ had PPE. The median age of patients with empyema [72.0 months (IQR 68.0 months)] was lower than the patients with PPE [92.5 (IQR 80.0 months)] $(p=0.003)$. Children in the empyema group had significantly more dyspnea symptoms than the children with PPE $(p=0.022)$. Mean fever duration before hospitalization was similar in both groups. Streptococcus pneumoniae and group A streptococcus were the most common causes of empyema. All of the patients were treated with intravenous antibiotics. In addition to medical treatment, tube thoracostomy was performed in 59 of $70(84.3 \%)$ patients in empyema group; $27(45.8 \%)$ of them required intrapleural fibrinolysis also. In the presence of antibiotic treatment failure or in cases with moderate or large pleural effusion with loculations and clinical deterioration; it is necessary to perform drainage of the purulent fluid by tube thoracostomy, to add intrapleural fibrinolytics or to perform video-assisted thoracoscopic surgery (VATS), in order to enhance prompt recovery.

Key words: parapneumonic effusion, empyema, children.

Parapneumonic effusion (PPE) and empyema are most often seen as a complication of bacterial pneumonia and occasionally associated with atypical bacterial or viral pneumonia. Parapneumonic effusion is an exudate within the pleural space associated with underlying pneumonia. Parapneumonic effusions have traditionally been classified into three categories, which can be thought of as different stages from a continuum disease spectrum: uncomplicated PPEs, complicated PPEs, and empyemas. The term uncomplicated PPE denotes an effusion that resolves with the antibiotic therapy prescribed for pneumonia. Complicated PPEs require drainage of pleural fluid by the interventions of repeated thoracentesis, thoracostomy tube drainage, fibrinolysis, video-assisted thoracoscopic surgery (VATS) and open thoracotomy for cure, in addition to antibiotics ${ }^{1-4}$. Empyema is characterized as the aspiration of pus by thoracentesis and is considered the last stage of a PPE; as such, it must always be drained. Therefore, empyemas are, by definition, complicated PPEs. Streptococcus pneumoniae is the most common agent of empyema in all ages beyond the neonatal period 3,5 . After the introduction of conjugated Haemophilus influenzae type B and conjugated pneumococcal vaccine in childhood vaccination schedule, methicillin-sensitive Staphylococcus aureus (MSSA), community acquired methicillin-resistant $S$. aureus (MRSA) 
and Streptococcus pyogenes are becoming increasingly frequent organisms. Optimal management of PPE is currently controversial. The aims of this study were to describe and compare demographic characteristics, clinical, laboratory, microbiological findings and treatment modalities for hospitalized patients with the diagnosis of PPE or pleural empyema.

\section{Material and Methods}

We retrospectively evaluated consecutive patients with PPE and pleural empyema who were admitted to our hospital from January 2006 to June 2015. Posteroanterior chest X-ray and ultrasound imaging were available for all of the patients. Chest CT had been performed for the patients with the suspicion of necrotizing pneumonia, parenchymal abscesses or bronchopleural fistulae. Diagnostic thoracentesis had been performed in patients who had pleural fluid on ultrasound imaging more than $1 \mathrm{~cm}$. The terms of PPE and pleural empyema were based on pleural fluid findings except patients who had $<1 \mathrm{~cm}$ pleural fluid suggestive of empyema with ultrasonographic view. Pleural empyema was defined as purulent pleural fluid appearance. In addition to purulent appearance, the presence of a pleural fluid $\mathrm{pH}<7.20$, a glucose level $<40 \mathrm{mg} / \mathrm{dl}$ and a lactate dehydrogenase (LDH) level >1000 IU and/or positive Gram stain and/or positive pleural fluid cultures. Uncomplicated PPE was defined as: if the aspirated fluid is nonpurulent, and having $\mathrm{pH}>7.20$, glucose level $>40 \mathrm{mg} /$ $\mathrm{dl}$, LDH level $<1000$ IU, negative Gram stain and negative pleural fluid cultures.

The medical records of patients were reviewed in respect of age, sex, history of cough, dyspnea, chest pain, abdominal pain, physical examination findings and previous antibiotic treatment before hospitalization. It was also questioned whether the patient received conjugated Haemophilus influenza type b (Hib) and conjugated pneumococcal vaccine or not. Haemophilus influenza type $\mathrm{b}$ vaccine has been put into practice routinely since 2006 in Turkey. The 7-valent pneumococcal conjugate vaccine (PCV7) was added to the national immunization schedule for children younger than 2 years in 2008 in our country. In 2011 this was replaced with the 13-valent pneumococcal conjugate vaccine (PCV13). The results of laboratory analyses that included complete blood count, C-reactive protein (CRP), erythrocyte sedimentation rate (ESR), pleural fluid cellular and biochemical findings, blood and pleural fluid culture were noted. Blood and pleural fluid cultures and antimicrobial susceptibility tests were performed with standard methods. S. pneumoniae polymerase chain reaction (PCR) and serotype identification test were used as available by Bio-Plex multiplex antigen detection method. If co infection was suspected by the means of beta-lactam use without improvement, enzyme immune assay (EIA) tests for Mycoplasma pneumoniae and Chlamydophila pneumoniae Ig M and Ig G had been performed.

The treatment decision steps were as follows: 1) if pleural fluid findings were compatible with empyema or there was an effusion on posteroanterior chest $\mathrm{x}$-ray involving $50 \%$ of the hemithorax, tube thoracostomy had been performed to drain the pleural cavity. Drainage tube had been inserted in the 5th or 6th intercostal on the medial axillary line and a negative pressure of $10-15 \mathrm{~cm} \mathrm{H}_{2} \mathrm{O}$ was applied. Proper positioning of the chest tube was confirmed radiologically at the end of the procedure; 2) if there was incomplete resolution of the effusion or presence of fibrin strands, loculation and/or septations on ultrasonography, fibrinolytic therapy was

Table I. Bacteria Isolated by Culture of Pleural Fluid Samples from Children with Empyema According to the Vaccination Status.

\begin{tabular}{lcccccc}
\hline \multicolumn{1}{c}{ Groups } & $\begin{array}{c}\text { Fully } \\
\text { vaccinated } \\
\text { with Hib } \\
\text { vaccine }\end{array}$ & $\begin{array}{c}\text { At least one } \\
\text { dose of Hib } \\
\text { vaccine }\end{array}$ & $\begin{array}{c}\text { Fully } \\
\text { vaccinated } \\
\text { with PCV7 }\end{array}$ & $\begin{array}{c}\text { At least one } \\
\text { dose PCV7 }\end{array}$ & $\begin{array}{c}\text { Fully } \\
\text { vaccinated } \\
\text { with PCV13 }\end{array}$ & $\begin{array}{c}\text { At least } \\
\text { one dose } \\
\text { PCV13 }\end{array}$ \\
\hline Empyema (n) & 31 & 6 & 15 & 13 & 8 & 3 \\
Organisms & $\begin{array}{c}\text { S. pneumoniae } \\
\text { S. pyogenes } \\
\text { P. fluorescens }\end{array}$ & S. aureus & $\begin{array}{c}\text { S. pneumoniae } \\
\text { P. fluorescens }\end{array}$ & $\begin{array}{c}\text { S. pneumoniae } \\
\text { S. aureus }\end{array}$ & $\begin{array}{c}\text { Viridans } \\
\text { Streptococcus } \\
\text { S. pyogenes }\end{array}$ & $\begin{array}{c}\text { S. aureus } \\
\text { (n) }\end{array}$ \\
\hline
\end{tabular}


Table II. Clinical Characteristics of Children with Parapneumonic Effusion (PPE) and Empyema.

\begin{tabular}{lccc}
\hline & \multicolumn{2}{c}{ Groups } & \\
\cline { 2 - 3 } & PPE & Empyema & P \\
\hline $\begin{array}{l}\text { Mean duration of fever (days), } \\
\text { median (IQR) }\end{array}$ & $7.0(6.0)$ & $8.5(7.0)$ & 0.172 \\
Cough, n (\%) & $42(40.8)$ & $61(59.2)$ & 0.487 \\
Dyspnea, n (\%) & $9(24.3)$ & $28(75.7)$ & 0.021 \\
Tachypnea, n (\%) & $17(34.7)$ & $32(65.3)$ & 0.350 \\
Chest pain, n (\%) & $16(36.4)$ & $28(63.6)$ & 0.571 \\
Abdominal pain, n (\%) & $6(28.6)$ & $15(71.4)$ & 0.251 \\
\hline
\end{tabular}

IQR: interquartile range

administered through the chest tube. Urokinase was used as a fibrinolytic agent. Thoracostomy tube was left in place, until $1 \mathrm{~mL} / \mathrm{kg}$ per day for 24 hours fluid had been drained through to tube 3 ) if pleural drainage was ineffective or multiple loculations/septations persisted despite fibrinolytic therapy, VATS or decortication was performed. For decortication operation, patients were referred to an another hospital. Initial empirical antibiotic treatment was nonpseudomonal third generation cephalosporine in all of the patients. The antibiotic therapy was modulated according to the patient's response to treatment or antibiotic sensitivity results during hospitalization. The antibiotic treatment was administrated intravenously until steady clinical improvement was provided. Thereafter antibiotic treatment was continued by oral route for total duration of 4-6 weeks. Antibiotic treatment regimens, interventional or surgical procedures, length of in hospital stay were recorded in all of the patients.

\section{Statistical analysis}

Shapiro-Wilk test was used to test the normality of continuous variables (age, sex, vaccination status, neutrophils, lymphocyte etc.). Descriptive data were expressed as the mean \pm standard deviation (SD), skewed data were shown as median and interquartile range (IQR), and absolute number or percentage (\%). Differences between groups were assessed using Pearson's $\chi 2$-test and the Mann-Whitney U-test. The level of significance adopted was $p<0.05$. The statistical analyses were performed using IBM SPSS Statistics 21.0 (IBM Corp. Released 2012. IBM SPSS Statistics for Windows, Version 21.0.
Armonk, NY: IBM Corp.).

\section{Results}

One hundred and sixteen children were enrolled in the study. Seventy $(60.34 \%)$ patients had pleural empyema and $46(39.65 \%)$ had PPE. Forty (57.14\%) and $24(52.17 \%)$ patients with empyema and PPE were male, respectively. The median age of children with empyema [72.0 months (IQR 68.0 months)] was significantly $(p=0.003)$ lower than the median age of children with PPE [92.5 (IQR 80.0 months)]. The immunization status of all of the Study Group according to their birth date was as follows: 17 patients were fully vaccinated with PCV7, 21 patients received at least one dose PCV7, 10 patients were fully vaccinated with PCV13, 7 patients received at least one dose PCV13 and 54 of children were fully vaccinated with $\mathrm{Hib}$ vaccine, 32 of cases received at least one dose of Hib. According to the vaccination status bacteria isolated by culture of pleural fluid samples from children with empyema were demonstrated in Table I. Forty-five (28.12\%) patients had history of previous antibiotic treatment. Oral antibiotics had been commenced in seven patients in empyema group and 16 patients in PPE group. Twenty-two patients in empyema group had been treated with parenteral antibiotics at an another center. Clinical and laboratory characteristics of children with empyema and PPE were shown in Table II and Table III, respectively.

Pleural fluid samples obtained from 66 of 70 patients $(94.2 \%)$ with empyema were analyzed. Twenty of 66 patients $(30.3 \%)$ with empyema had positive pleural fluid cultures; four of them 
Table III. Laboratory Characteristics of Children with Parapneumonic Effusion and Empyema.

\begin{tabular}{llll}
\hline & \multicolumn{2}{c}{ Groups } & \\
\cline { 2 - 4 } Variables & PPE & Empyema \\
& Median (IQR) & Median (IQR) & $\mathrm{p}$ \\
\hline Hemoglobin $(\mathrm{g} / \mathrm{dl})$ & $11.4(2.6)$ & $10.6(2.1)$ & 0.004 \\
WBC $\left(10^{3} / \mathrm{mm}^{3}\right)$ & $13.4(8.4)$ & $404.0(12.9)$ & 0.070 \\
Thrombocyte $\left(10^{3} / \mathrm{mm}^{3}\right)$ & $352.5(211.0)$ & $235.0(217.5)$ & 0.099 \\
CRP $(\mathrm{mg} / \mathrm{L})$ & $166.0(190.5)$ & $65.0(167.0)$ & 0.090 \\
ASO $(\mathrm{IU} / \mathrm{ml})$ & $220.0(474.0)$ & $81.0(55.0)$ & 0.011 \\
ESR $(\mathrm{mm} /$ hour $)$ & $76.0(63.0)$ & 0.120 \\
\hline
\end{tabular}

CRP: C-reactive protein; ASO: antistreptolysin-O titer; ESR: erythrocyte sedimentation rate

(25\%) had both positive blood and pleural fluid cultures. The pleural fluid and blood culture and pleural fluid PCR results were demonstrated in Table IV. All of the S. pneumoniae isolates were susceptible to penicillin, ceftriaxone, clindamycin and clarithromycin. The S. aureus isolate was methicillin sensitive. Mycoplasma pneumoniae Ig M and Ig G are analyzed in 60 patients. Among culture negative cases $M$. pneumoniae Ig M positivity in 12 cases with empyema and in 15 cases with PPE were detected. Chlamydophila pneumoniae Ig $\mathrm{M}$ was positive in three cases with empyema and in three cases with PPE. No coinfection with $M$. pneumoniae or C. pneumoniae and an another organism was detected.

Ultrasound images of patients with PPE and empyema were demonstrated in Table V. Chest computed tomography (CT) was performed in 39 patients $(55.7 \%)$ with empyema and in 0 patients $(21.7 \%)$ with PPE. Necrotizing pneumonia was detected in 16 of 39 children with empyema, and three patients with PPE on chest CT scan. Pulmonary abscess was diagnosed in one child with empyema.

Clindamycin or clarithromycin were added to initial empirical nonpseudomonal third generation cephalosporin therapy in eight $(6.9 \%)$ patients and in $46(39.6 \%)$ patients, respectively. Tube thoracostomy was performed in $59(\% 84.3)$ patients with empyema and in $6(\% 13)$ patients with PPE. Intrapleural fibrinolytic treatment was required in 27 $(34.1 \%)$ patients with empyema. Fibrinolytic treatment was administered after median 3 days (range: 2-5 days) of hospitalization, and median 3 doses (range: 2-5 doses). Duration of chest drainage was median 8 days (range:

Table IV. Bacteria Isolated by Culture of Blood and Pleural Fluid Samples and by PCR of Pleural Fluid Samples from Children with Empyema.

\begin{tabular}{lccc}
\hline Organism & $\begin{array}{c}\text { Blood } \\
\text { culture } \\
\text { (n:70) }\end{array}$ & $\begin{array}{c}\text { Pleural fluid } \\
\text { culture } \\
\text { (n: 66) }\end{array}$ & $\begin{array}{c}\text { Pleural fluid } \\
\text { PCR } \\
\text { (n: 6) }\end{array}$ \\
\hline Streptococcus pneumoniae & 2 & 9 & 6 \\
S. pyogenes & 1 & 3 & (serotypes1, 3, 4, 5, 8, 14) \\
Viridans streptococcus & 0 & 2 & NA \\
Peptostreptecoccus spp. & 0 & 1 & NA \\
Staphylococcus aureus & 0 & 1 & NA \\
Haemophilus influenzae & 1 & 1 & NA \\
Stenotrophomonas maltophilia & 0 & 1 & NA \\
Flavimonas oryzihabitans & 0 & 1 & NA \\
Pseudomonas fluorescens & 0 & 1 & NA \\
\hline
\end{tabular}


3-23 days). Three children were treated with VATS. VATS was performed earliest at 3 days and latest at 6 days after hospitalization. Decortication operation was performed in five children after median 12 days (range: 5-27 days) of hospitalization. Side effects attributable to fibrinolytic treatment were recorded in 9 patients, including mild chest pain (3 patients), transient fever (4 patients), and mild bleeding (2 patients). Complications of tube thoracostomy were recorded in 4 patients, including pneumothorax (3 patients) and bronchopleural fistula (1 patient).

The median duration of hospital stay of patients with empyema treated with tube drainage and fibrinolytic treatment was 21 days (range: 12-56 days). The median duration of hospital stay of patients with PPE treated with tube drainage was 22 days (range: 8-35 days). The median duration of hospital stay [16 days (IQR 9 days)] of patients with empyema was significantly $(p<0.001)$ longer than patients with PPE [ $(9$ days, (IQR 8 days)]. None of the patient died. The mean duration of outpatient follow-up was 4 months (IQR 12 months).

\section{Discussion}

Parapneumonic effusion is a known complication of mainly bacterial pneumonia in children. Viral or mycoplasmal pneumonia may also cause PPE with a ratio of up to $20 \%$. The incidence of PPE and empyema is steadily increasing according the recent reports. Empyema has been reported in 6.3 to 23 of 1,000 admissions among children ${ }^{6,7}$. After the PCV7 introduction, despite rates of bacterial pneumonia and invasive pneumococcal disease decreased, annual empyema associated hospitalization rates in children increased. Authors thought that this is likely the result of serotype replacement with non-vaccine serotypes, or increasing $\mathrm{MRSA}^{8}, 10$. In the present study; we could not compare the two groups with respect of PCV7 or PCV13, since the patients of both groups were vaccinated partly and heterogeneously PCV7 or PCV13.

Parapneumonic effusion and empyema are more common in boys than girls and are more frequently encountered in infants and young children ${ }^{11}$. Number of girls and boys were similar for patients with PPE and empyema in the present study. The median age at presentation of patients with empyema, was lower than the patients with PPE in our study. A comparison had been made between hospitalized patients with community acquire pneumonia (CAP) and empyema in a United States of America (USA) study. Empyema had been reported in 153 of 540 (28.3\%) children with pneumonia. In concordance with our results, patients with empyema were more likely to be older than 3 years in this study ${ }^{12}$. The present study did not include patients with CAP.

The presenting symptoms of PPE are frequently subtle and usually similar with classic symptoms of pneumonia such as cough, dyspnea, fever, malaise, loss of appetite. The clinical features of empyema are fever, cough, dyspnea tachypnea, lethargy, increasing oxygen requirement and respiratory distress. Pleural and abdominal pain were also seen ${ }^{13}$. Fever was the most common presenting symptom of children with PPE and empyema in our study. All other presenting symptoms except dyspnea were similar in both groups. Dyspnea is more significant in patients with empyema than patients with PPE. It was reported that children with empyema had more chest pain and dyspnea at admission and had a significantly longer duration of fever compared with effusion and CAP group in the pediatric studies $2,11,14,15$. On the contrary; mean duration of fever before hospitalization was similar in both groups in our study. We thought that two groups of our study had complicated or

Table V. Ultrasound Images of Patients with Parapneumonic Effusion and Empyema.

\begin{tabular}{cccccc}
\hline & PPE & & \multicolumn{3}{c}{ Empyema } \\
Pleural fluid location & $\begin{array}{c}\text { Median depth, mm } \\
\text { (IQR) }\end{array}$ & & $\begin{array}{c}\text { Median depth, mm } \\
(\text { IQR) }\end{array}$ & $\begin{array}{c}\text { With septation } \\
(\mathrm{n})\end{array}$ & $\begin{array}{c}\text { Without } \\
\text { septation (n) }\end{array}$ \\
\hline Right & $14.0(10.0)$ & & $22.0(17.0)$ & 18 & 22 \\
Left & $11.0(14.0)$ & & $17.0(18.0)$ & 10 & 20 \\
\hline
\end{tabular}

IQR: interquartile range; PPE: parapneumonic effusion 
noncomplicated pleural effusion and none of them were uncomplicated CAP.

Pleural fluid culture positivity rate might be as low as $8 \%$, in the patients who had been treated with antibiotics prior to thoracentesis ${ }^{16}$. Similar to other pediatric reports, $16.4 \%$ of cultures of pleural fluid in our patients were detected as positive. Nearly one-third of our patients had history of previous antibiotic treatment. Molecular techniques can cover a broader range of pathogens and serotypes. Moreover, prior antibiotic treatment does not influence to the results of these techniques. But these are not employed routinely in laboratories for clinical use $\mathrm{e}^{2,17}$. Streptococcus pneumoniae is the most common cause of CAP with or without empyema. Pleural empyema develops in $75 \%$ of patients with $S$. aureus pneumonia. The incidence of Hib empyema decreased after the introduction of the Hib vaccination. Group A streptococcus, other streptococcal species, $M$. pneumoniae and gram-negative organisms are less common causes of empyema in children. Recently community acquired MRSA has been found to be an important causative organism of empyema $2,7,13,16-19$. In our study, S. pneumoniae was the most common pathogen, followed by group A streptococcus. In a recent multicenter study from Turkey, S. pneumoniae serotypes were determined in 156 children with empyema, irrespective of their vaccination status. $S$. pneumoniae was detected in 53 of 156 patients (34\%) by PCR and serotypes were specified in 33 of them. The most common pneumococcal serotypes in this study were 1 and 5, which are covered by both PCV10 and PCV13, but serotype 3 is covered only by PCV-1320. Defined serotypes of five of our patients, as a part of this laboratory-based surveillance, are 1, 3, 4, 5 , and14.

Mycoplasma pneumoniae is one of the most common respiratory pathogens. The course of illness is usually benign and is rarely associated with pulmonary complications. PPE due to M. pneumoniae has been reported in $4-20 \%$ of patients with CAP. Although PPE is generally small, unilateral and does not require chest tube insertion, it can be massive and bilateral1,21-25. In a retrospective observational study involving 121 hospitalized children and adolescent patients with CAP/ PPE, M. pneumoniae without co-infection was detected in 34 and M. pneumoniae/S. pneumoniae co-infection was found in nine patients. Other responsible organisms were reported as $S$. pneumoniae in 36 and $S$. aureus in 31 patients. Authors concluded that $M$. pneumoniae related PPE was milder than that was caused by other organisms, but its course was longer ${ }^{26}$. Massive pleural effusion and empyema secondary to M. pneumoniae infection has been reported as case series or single case reports, 27-32. In our study, M. pneumoniae related empyema and PPE were required chest tube drainage and tube thoracostomy with intrapleural fibrinolysis that M. pneumoniae related empyema and PPE might be massive.

Diagnostic imaging methods play an important role in the diagnosis and management of PPE and empyema. The principal imaging methods are chest X-ray, chest ultrasonography, and chest CT. Posteroanterior or anteroposterior chest X-ray is frequently used as the first investigation method to suggest the presence of a parapneumonic collection, however it cannot definitively establish the presence of empyema. Chest ultrasonography confirms the presence of a pleural fluid and it useful to detect amount of fluid, fibrinous septations, debris or loculations in the pleural space. It may be also used to guide thoracentesis or drain placement ${ }^{11,33}$. Some authors suggest that pleural debris, loculations and septations are better identified by using ultrasonography rather than $\mathrm{CT} \operatorname{scan}^{34,35}$. In a study of 30 pediatric patients, CT scanning was not found so helpful in differentiating empyema from $\mathrm{PPE}^{36}$. The authors suggested that chest CT scan should not be performed routinely for the diagnosis of empyema or PPE. A small retrospective review comparing USG and CT found that CT had no advantage in most cases. Authors considered that CT should be used for distinguishing parenchymal abscesses from empyema or to detect broncho-pleural fistulae as a complication of empyema ${ }^{35}$. In our study chest USG was a primary choice of imaging. In the present study, the chest CT scan was found useful to detect necrotizing pneumonia and lung abscesses.

The purpose of the treatment of empyema is lung reexpansion for improving respiratory function. Drainage of the pleural purulent fluid is required in most of the patients in 
conjunction to intravenous antibiotics. For this purpose, repeated thoracentesis, tube drainage with thoracostomy, tube drainage and fibrinolytic, VATS or open decortications are performed ${ }^{37}$. Empirical antibiotic treatment should cover S. pneumoniae, S. pyogenes and S. aureus. Some authors suggested that clindamycin may be used as the first empiric treatment option in children in addition to ceftriaxone for the purpose of covering community acquired MRSA, anaerobes and toxigenic group A streptococcus strains as possible responsible agents ${ }^{16,38,39}$. In our study, clindamycin was added to ceftriaxone mainly for patients with empyema. We found that M. pneumoniae might be responsible for PPE or empyema as an only pathogen. Because the recommended first line empirical treatment for PPE and empyema is beta-lactams, adding macrolide antibiotics should be kept in mind in patients who show no improvement with initial antibiotics. In these patients, serological tests should be done for establishment of $M$. pneumoniae infection. The optimal modality for drainage is controversial. Repeated thoracentesis is not recommended in infants. If there is an effusion on posteroanterior chest X-ray involving $50 \%$ of the hemithorax or empyema is revealed in pleural fluid analysis, pleural space requires drainage with tube thoracostomy. If there are septation, loculation, organized and thick collection on ultrasonographic imaging, fibrinolytic therapy should be performed for fibrin break down. The common fibrinolytic agents are urokinase, streptokinase and tissue plasminogen activator (tPA). In retrospective and prospective studies, fibrinolytic therapy has been shown to be superior to chest tube drainage alone when chest tube drainage is failed ${ }^{40-48}$. Recently, VATS has been increasingly selected as an option for treatment of childhood empyema. Pediatric prospective studies showed that fibrinolytic therapy and VATS were equal to each other and there were not any differences in hospital stay, days with drainage, or treatment failure between the two treatment options ${ }^{50-52}$. In a pediatric retrospective case-control study, it was shown that VATS did not result in a significantly shorter hospital stay or fewer complications compared with the conservative approach of chest drainage with or without fibrinolysis ${ }^{2}$. As a result of reviewing the four randomized controlled study involving 194 children, there is no evidence that VATS is more effective than fibrinolytic treatment and authors suggested that nonoperative management should be the first line of therapy, if feasible. If pleural space drainage with fibrinolytic therapy is ineffective, VATS should be performed without delay ${ }^{53}$. In our study, tube thoracostomy and antibiotic treatment was successful especially for most of the patients with empyema. When this treatment failed, intrapleural fibrinolysis was applied before VATS. Open decortication was reserved for all of these treatment failures.

We concluded that, patients with empyema were younger than the patients with PPE. Duration and frequency of fever were similar in patients with PPE or empyema, dyspnea is a more frequent presenting symptom of patients with empyema. S. pneumoniae and group A streptococcus had been detected as the most common causes of empyema, however pleural fluid culture positivity rate was low. M. pneumoniae might be responsible for PPE or empyema as a single pathogen. Furthermore $M$. pneumoniae related empyema might be as massive as requiring tube thoracostomy and intrapleural fibrinolysis. Adding macrolide antibiotic to initial beta-lactam antibiotics should be kept in mind in patients who show no improvement. Chest USG was a useful diagnostic imaging modality for PPE and empyema. Chest CT scan might be required to detect necrotizing pneumonia and lung abscesses. Tube thoracostomy and antibiotic treatment were successful treatment modalities for most of the patients.

\section{REFERENCES}

1. Light RW. Parapneumonic effusions and empyema. Proc Am Thorac Soc 2006; 3: 75-80.

2. Grisaru-Soen G, Eisenstadt M, Paret G, et al. Pediatric parapneumonic empyema risk factors, clinical characteristics, microbiology, and management. Pediatr Emerg Care 2013; 29: 425-429.

3. Byington CL, Korgenski K, Daly J, et al. Impact of the pneumococcal conjugate vaccine on pneumococcal parapneumonic empyema. Pediatr Infect Dis J 2006; 25: $250-254$.

4. Porcel JM. Distinguishing complicated from uncomplicated parapneumonic effusions. Curr Opin Pulm Med 2015; 21: 346-351.

5. Chiu CY, Chiang LM, Chen TP. Mycoplasma pneumoniae infection complicated by necrotizing pneumonitis with massive pleural effusion. Eur J Pediatr 2006; 165: 275-277. 
6. Kurt BA, Winterhalter KM, Connors RH, et al. Therapy of parapneumonic effusions in children: video-assisted thoracoscopic surgery versus conventional thoracostomy drainage. Pediatrics 2006; 118: 547-553.

7. Wheeler JG, Jacobs RF. Complications of Pneumonia. In: Cherry JD (ed). Feigin and Cherry's Textbook of Pediatric Infectious Diseases (7th ed). Philadelphia, 2014: 306-322.

8. Li ST, Tancredi DJ. Empyema hospitalizations increased in US children despite pneumococcal conjugate vaccine. Pediatrics 2010; 125: 26-33.

9. Guevara M, Ezpeleta C, Gil-Setas A, et al. Reduced incidence of invasive pneumococcal disease afterintroduction of the 13-valent conjugate vaccine in Navarre, Spain, 2001-2013. Vaccine 2014; 32: 2553-2562.

10. Kaplan SL, Barson WJ, Lin PL, et al. Early trends for invasive pneumococcal infections in children after the introduction of the 13-valent pneumococcal conjugate vaccine. Pediatr Infect Dis J 2013; 32: 203-207.

11. Balfour-Lynn IM, Abrahamson E, Cohen G, et al. BTS guidelines for the management of pleural infection in children. Thorax 2005; 60: 1-21.

12. Byington CL, Spencer LY, Johnson TA, et al. An epidemiological investigation of a sustained high rate of pediatric parapneumonic empyema: risk factors and microbiological associations. Clin Infect Dis 2002, 34: 434-440.

13. Winnie GB, Lossef SV. Pleurisy, Pleural Effusions, and Empyema. In: Kliegman RM, Stanton BF, Geme JW, Schor NF, Behrman RE (ed). Nelson Textbook of Pediatrics (19th ed). Philadelphia: Elsevier, 2011: 1505-1509.

14. Dass R, Deka NM, Barman H, et al. Empyema thoracis: Analysis of 150 cases from a tertiary care centre in North East India. Indian J Pediatr 2011; 78: 1371-1377.

15. Kumar A, Sethi GR, Mantan M, et al. Empyema thoracis in children. Indian Pediatr 2013; 50: 879-882.

16. Schultz KD, Fan LL, Pinsky J, et al. The changing face of pleural empyemas in children: epidemiology and management. Pediatrics 2004; 113: 1735-1740.

17. Sakran W, Ababseh ZED, Miron D, et al. Thoracic empyema in children: Clinical presentation, microbiology analysis and therapeutic options. J Infect Chemother 2014; 20: 262-265.

18. Blaschke AJ, Heyrend C, Byington CL, et al. Molecular analysis improves pathogen identification and epidemiologic study of pediatric parapneumonic empyema. Pediatr Infect Dis J 2011; 30: 289-294.

19. Sahn SA. Diagnosis and management of parapneumonic effusions and empyema. Clin Infect Dis 2007; 45: 1480-1486.

20. Ceyhan M, Ozsurekci Y, Gürler N, et al. Distribution of Streptococcus pneumoniae serotypes that cause parapneumonic empyema in Turkey. Clin Vaccine Immunol 2013; 20: 972-976.

21. John SD, Ramanathan J, Swischuk LE. Spectrum of clinical and radiographic findings in pediatric mycoplasma pneumonia. Radiographics 2001; 21: 121-131.
22. Vervloet LA, Vervloet VEC, Junior MT, et al. Mycoplasma pneumoniae-related community-acquired pneumonia and parapneumonic pleural effusion in children and adolescents. J Bras Pneumol 2012; 38: 226-236.

23. Neumayr L, Lennette E, Kelly D, et al. Mycoplasma disease and acute chest syndrome in sickle cell disease. Pediatrics 2003; 112: 87-95.

24. Aydemir C, Ustundağ GH, Eldeş N, et al. Massive parapneumonic effusion caused by Mycoplasma pneumoniae in a child: A case report. Tuberk Toraks 2008; 56: 310-314.

25. Hsieh SC, Kuo YT, Chern MS, et al. Mycoplasma pneumonia: clinical and radiographic features in 39 children. Pediatr Int 2007; 49: 363-367.

26. Vervloet LA, Vervloet VE, Tironi Junior $M$, et al. Mycoplasma pneumoniae-related community-acquired pneumonia and parapneumonic pleural effusion in children and adolescents. J Bras Pneumol 2012; 38: 226-236.

27. Wang RS, Wang SY, Hsieh KS, et al. Necrotizing pneumonitis caused by mycoplasma pneumoniae in pediatric patients report of five cases and review of literature. Pediatr Infect Dis J 2004; 23: 564-567.

28. Othman N, Yip CW, Samat NA. Mycoplasma pneumoniae infection complicated by empyema: A rare presentation. Med J Malaysia 2005; 60: 389-391.

29. Patra PK, Babu TA. Unusual complication of Mycoplasma pneumonia in a five-year-old child. Australas Med J 2013; 6: 73-74.

30. Oermann C, Sockrider MM, Langston C. Severe necrotizing pneumonitis in a child with Mycoplasma pneumoniae infection. Pediatr Pulmonol 1997; 24: 61-65.

31. Aydemir C, Ustundag GH, Eldes N, et al. Massive parapneumonic effusion caused by Mycoplasma pneumoniae in a child: a case report. Tuberk Toraks 2008; 56: 310-314.

32. Vervloet LA, Marguet C, Camargos PA. Infection by Mycoplasma pneumoniae and its importance as an etiological agent in childhood community-acquired pneumonias. Braz J Infect 2007; 11: 507-514.

33. Islam $\mathrm{S}$, Calkins $\mathrm{CM}$, Goldin $\mathrm{AB}$, et al. The diagnosis and management of empyema in children: a comprehensive review from the APSA Outcomes and Clinical Trials Committee. J Pediatric Surg 2012; 47: 2101-2110.

34. Calder A, Owens CM. Imaging of parapneumonic pleural effusions and empyema in children. Pediatr Radiol 2009; 39: 527-537.

35. Kurian J, Levin TL, Han BK, et al. Comparison of ultrasound and CT in the evaluation of pneumonia complicated by parapneumonic effusion in children. AJR Am J Roentgenol 2009; 193: 1648-1654.

36. Donnelly LF, Klosterman LA. CT appearance of parapneumonic effusions in children: findings are not specific for empyema. Am J Roentgenol 1997; 169: 179-182.

37. Ekingen G, Güvenç BH, Sözübir S, et al. Fibrinolytic treatment of complicated pediatric thoracic empyemas with intrapleural streptokinase. Eur J Cardiothorac Surg 2004; 26: 503-507. 
38. Buckingham SC, King MD, Miller ML. Incidence and etiologies of complicated parapneumonic effusions in children, 1996 to 2001. Pediatr Infect Dis J 2003; 22: 499-504.

39. Walker W, Wheeler R, Legg J. Update on the causes, investigation and management of empyema in childhood. Arch Dis Child 2011; 96: 482-488.

40. Yao CT, Wu JM, Liu CC, et al. Treatment of complicated parapneumonic pleural effusion with intrapleural streptokinase in children. Chest 2004; 125: 566-571.

41. Misthos P, Sepsas E, Konstantinou M, et al. Early use of intrapleural fibrinolytics in the management of postpneumonic empyema. A prospective study. Eur J Cardiothorac Surg 2005; 28: 599-603.

42. Kiliç N, Celebi S, Gürpinar A, et al. Management of thoracic empyema in children. Pediatr Surg Int 2002; 18: 21-23.

43. Cochran JB, Tecklenburg FW, Turner RB. Intrapleural instillation of fibrinolytic agents for treatment of pleural empyema. Pediatr Crit Care Med 2003; 4: 39-43.

44. Ulku R, Onat S, Kiliç N. Intrapleural fibrinolytic treatment of multiloculated pediatric empyemas. Minerva Pediatr 2004; 56: 419-423.

45. Bouros D, Antoniou KM, Chalkiadakis G, et al. The role of video-assisted thoracoscopic surgery in the treatment of parapneumonic empyema after the failure of fibrinolytics. Surg Endosc 2002; 16: 151-154.

46. Thomson AH, Hull J, Kumar MR, et al. Randomised trial of intrapleural urokinase in the treatment of childhood empyema. Thorax 2002; 57: 343-347.
47. Bianchini MA, Ceccarelli PL, Repetto P, et al. Oncedaily intrapleural urokinase treatment of complicated parapneumonic effusion in pediatric patients. Turk J Pediatr 2010; 52: 274-277.

48. Chen JP, Lue KH, Liu SC, et al. Intrapleural urokinase treatment in children with complicated Parapneumonic effusion. Acta Paediatr Taiwan 2006; 47: 61-66.

49. Aydoğan M, Aydoğan A, Ozcan A, et al. Intrapleura streptokinase treatment in children with empyema. Eur J Pediatr 2008; 167: 739-744.

50. Cohen E, Weinstein M, Fisman DN. Cost-effectiveness of competing strategies for the treatment of pediatric empyema. Pediatrics 2008; 121: 1250-1257.

51. Sonnappa S, Cohen G, Owens CM, et al. Comparison of urokinase and video-assisted thoracoscopic surgery for treatment of childhood empyema. Am J Respir Crit Care Med 2006; 174: 221-227.

52. St Peter SD, Tsao K, Spilde TL, et al. Thoracoscopic decortication vs tube thoracostomy with fibrinolysis for empyema in children: a prospective, randomized trial. Pediatr Surg 2009; 44: 106-111.

53. Krenke K, Peradzyńska J, Lange J, et al. Local treatment of empyema in children: a systematic review of randomized controlled trials. Acta Paediatr 2010; 99: 1449-1453. 